\title{
Understanding effects of armed conflict on health outcomes: the case of Nepal
}

Bhimsen Devkota ${ }^{12^{*}}$, Edwin R van Teijlingen ${ }^{3}$

\begin{abstract}
Objective: There is abundance of literature on adverse effects of conflict on the health of the population. In contrast to this, sporadic data in Nepal claim improvements in most of the health indicators during the decadelong armed conflict (1996-2006). However, systematic information to support or reject this claim is scant. This study reviews Nepal's key health indicators before and after the violent conflict and explores the possible factors facilitating the progress.

Methods: A secondary analysis has been conducted of two demographic health surveys-Nepal Family Health Survey (NFHS) 1996 and Nepal Demographic and Health Survey (NDHS) 2006; the latter was supplemented by a study carried out by the Nepal Health Research Council in 2006.

Results: The data show Nepal has made progress in 16 out of 19 health indicators which are part of the Millennium Development Goals whilst three indicators have remained static. Our analysis suggests a number of conflict and non-conflict factors which may have led to this success.

Conclusion: The lessons learnt from Nepal could be replicable elsewhere in conflict and post-conflict environments. A nationwide large-scale empirical study is needed to further assess the determinants of Nepal's success in the health sector at a time the country experienced a decade of armed conflict.
\end{abstract}

\section{Background}

Violent conflicts pose a challenge to human civilisations, human health and health systems [1-3]. Epidemiological studies indicate that war ranks among the top-ten causes of death worldwide [4-6]. Populations affected by armed conflict experience severe public health consequences mediated by population displacement, food scarcity, and the collapse of basic health services, which together often give rise to complex humanitarian emergencies $[7,8]$. Conflict has both direct and indirect effects on people's health and on the overall health system [8]. Armed conflicts can also cause the displacement of people and an increase in infectious diseases $[2,9]$.

Nepal recently emerged from a decade-long violent conflict (1996 to 2006). This violent conflict had an effect on both the population's health and the health care system[10-12].It led to over 13,000 fatalities [13],

\footnotetext{
* Correspondence: b.devkota@abdn.ac.uk

${ }^{1}$ Section of Population Health, School of Medicine and Dentistry, AB 25, 2ZD, University of Aberdeen, Scotland, UK

Full list of author information is available at the end of the article
}

the disappearance of at least 1,200 people $[10,14]$, the disablement of thousands of people, and the internal displacement of many more [14,15]. Over 1,000 health posts in rural areas were destroyed [16], more than a dozen health workers had been killed and many others were harassed, kidnapped, threatened and prosecuted by the warring factions $[14,17,18]$. The conflict aggravated the already poor health services as one third of Nepal's health centres is in rural areas (where some of the fighting was heaviest) and often operates without health staff [19-21]. Torture and sexual-abuse related to insurgency were also prominent $[11,22,23]$, and the conflict also hindered health programmes implemented by non-governmental organisations [24,25].

The Maoist rebels put restrictions on field staff mobility and both the security forces and rebels tried to stop public gatherings focused on health-related awareness. Furthermore, the Maoists objected to the implementation of the Community Drug Programme (CDP) by opposing the minimal fees associated with it.

Nepal and 146 other countries adopted the Millennium Development Goals (MDGs) in 2000 [26]. The MDGs 
Table 1 Millennium Development Goals (MDGs)

\author{
Eradicate Extreme Poverty \& Hunger \\ Achieve Universal Primary Education \\ Promote Gender Equality \& Empower Women \\ Reduce Child Mortality \\ Improve Maternal Health \\ Combat HIV/AIDS, Malaria \& Other Diseases \\ Ensure Environmental Sustainability \\ Develop a Global Partnership for Development
}

are eight targets to be achieved by 2015 to overcome the key global development challenges (Table 1). Hence MDGs are a yardstick against which we can measure progress made by the member countries (or lack thereof) in terms of health and development indicators. Three out of eight goals (i.e. MGD 4-6) relate directly to health, and health is an important contributor to several other MDGs.

Amidst the civil war, Nepal appeared to have made improvements in its human development index, life expectancy and child and maternal health indicators $[18,21,27]$. Some of the publicly available datasets suggest that Nepal has made considerable progress on certain key health indicators, however for few other indicators the progress seems to have stagnated. In recognition of its progress on reduction in maternal and child mortality rate and improvement on other health indicators, the US (United States) Government recently commended Nepal under its Global Health Initiative Programme. Nepal is only one of eight countries receiving this award. Nepal's progress seems puzzling as it contradicts our common understanding that civil conflict is an impediment for improving the health services. It raises a question whether the progress was real, and if so, what could have contributed to achieve this progress? The possible hypotheses could be that Nepal's violent conflict: i) worsened health indicators; ii) improved health indicators; or iii) had a mixed effect, i.e. improvement in some and stagnation or deterioration in other indicators. This paper analyses Nepal's main health indicators before and after the conflict and offers some possible explanations for the observed changes.

\section{Methods}

This paper is based on secondary analysis, in which "data collected by one researcher are re-analysed by another investigator usually to test new research hypotheses" [28]. Thus secondary analysis uses data which have already been collected and the research question might, or might not, have formed part of the remit of the original study design. In this paper we draw upon data from three main sources: i) demographic health surveys 1996, which were called Nepal Family Health Survey (NFHS) in 1996 [29] and Nepal Demographic Health Survey (NDHS) in 2006 [30]; ii) a study led by the first author under the auspicious of Nepal Health Research Council (NHRC) in 2006 [27]; and iii) data from the Ministry of Health and Population (MOHP) and similar sources. The NFHS 1996 used household questionnaire and women interviews while the NDHS 2006 used household interviews and separate interviews with women and men. This paper compares health indicators based on the household interviews (particularly demographic characteristics, water, sanitation, nutritional status of children) and women interviews (e.g. education, marriage, childbirth, family planning, fertility, maternity care, immunisation, awareness of HIV/AIDS) in order to address gender biases whilst comparing the 1996 and 2006 data.

The NFHS 1996 and NDHS 2006 both used multistage systematic sampling; each covered all three ecological regions (i.e. mountain, hill and terai) and all the five development regions of Nepal (i.e. Eastern, Central, Western, Mid-western and Far-western regions). The NFHS 1996 covered 8,429 women aged 15-49, while the NDHS 2006 covered 10,793 women aged 15-49 and 4,397 men aged 15-59. Both surveys were conducted by the same two organisations-Macro International (technical support) and New Era ( a local research firm) under the aegis of the Department of Health Services. These conditions permit comparison of the NFHS 1996 and NDHS 2006 data. The sampling and data collection methods used in these two studies allow us to make a valid comparison for pre-and post-conflict juxtaposition. The analysis focuses on women (See notes in Table 2), since the 1996 study did not include interviews with men, while the coverage of all three eco-regions and cross-section of five development regions ensures the whole country is covered. Though the Maoist violence started in the western part of the country in 1996, it had spread all over Nepal by 2001, hence it was not possible to define 'conflict' and 'non-conflict' areas and disaggregate the data to make comparisons between these two areas.

There is a possibility that problems occurred during the data collection of the various surveys. The insecurity due to conflict made the survey data collection less reliable [31] since (a) parts of the country was not under Government control; and (b) Census enumerators might have been afraid to approach people whom they believed to be Maoist sympathisers as Census enumerators were working for the Government. Some of this may also have occurred during the data collection for the studies used in our secondary analysis.

The study conducted by the NHRC in 2006 covered 800 women with children under the age of two, 40 
Table 2 Main health indicators at the beginning (1996) and end of the conflict (2006)

\begin{tabular}{|c|c|c|c|c|c|c|c|c|c|}
\hline \multirow[t]{2}{*}{ MDG Goal } & \multirow[t]{2}{*}{ Health Indicators*,** } & \multirow{2}{*}{$\begin{array}{c}1996 \\
\text { (NFHS) }\end{array}$} & \multirow{2}{*}{$\begin{array}{c}2006 \\
\text { (NDHS) }\end{array}$} & \multirow[t]{2}{*}{ Difference } & \multirow[t]{2}{*}{ OR } & \multicolumn{2}{|c|}{$95 \% \mathrm{Cl}$} & \multirow{2}{*}{$\begin{array}{l}\text { NHRC } \\
2006\end{array}$} & \multirow{2}{*}{$\begin{array}{c}\text { MDG } \\
\text { Target } \\
2015\end{array}$} \\
\hline & & & & & & Lower & Upper & & \\
\hline \multirow{3}{*}{$\begin{array}{l}\text { GOAL1 } \\
\text { Eradicate extreme } \\
\text { poverty \& hunger }\end{array}$} & $\begin{array}{l}\text { 1. Percent of stunted children under } 3 \text { (height/ } \\
\text { age) }\end{array}$ & 56 & 42 & 14 & 1.756 & 1.003 & 3.077 & $\mathrm{Na}$ & 30 \\
\hline & $\begin{array}{l}\text { 2. Percentage of undernourished children under } 3 \\
\text { wasting (wt/height) }\end{array}$ & 11 & 15 & -4 & 0.700 & 0.3 .45 & 1.6109 & $\mathrm{Na}$ & 25 \\
\hline & 3. Underweight children under 3 (weight for age) & 42 & 35 & 7 & 1.344 & 0.759 & 2.381 & $\mathrm{Na}$ & 29 \\
\hline \multirow{3}{*}{$\begin{array}{l}\text { GOAL } 4 \\
\text { Reduce child } \\
\text { mortality }\end{array}$} & 4.Neonatal mortality rate $/ 1,000$ live births & 50 & 33 & 17 & 2.030 & 1.145 & 3.598 & $\mathrm{Na}$ & 16 \\
\hline & 5.Infant mortality rate $/ 1,000$ live births & 79 & 48 & 31 & 3.915 & 2.108 & 7.283 & $\mathrm{Na}$ & 34 \\
\hline & 6.Under 5 child mortality rate/1,000 live births & 118 & 61 & 57 & 2.059 & 1.491 & 2.843 & $\mathrm{Na}$ & 54 \\
\hline \multirow{2}{*}{$\begin{array}{l}\text { Intermediate } \\
\text { Indicator }\end{array}$} & 7. DPT 3 immunisation coverage $\%$ & 76 & 87 & 11 & 0.472 & 0.225 & 0.993 & 93 & 100 \\
\hline & 8. Measles vaccine coverage $\%$ & 57 & 85 & 28 & 0.233 & 0.118 & 0.460 & 91 & 90 \\
\hline \multirow{2}{*}{$\begin{array}{l}\text { GOAL } 5 \\
\text { Improve maternal } \\
\text { health }\end{array}$} & 9.Maternal mortality ratio/100,000 live births & 539 & 281 & 258 & 2.991 & 2.484 & 3.602 & $\mathrm{Na}$ & 134 \\
\hline & 10. Total fertility rate & 4.6 & 3.1 & 1.5 & 1.333 & 0.298 & 5.959 & $\mathrm{Na}$ & 2.4 \\
\hline \multirow[t]{4}{*}{$\begin{array}{l}\text { Intermediate } \\
\text { Indicator }\end{array}$} & $\begin{array}{l}\text { 11.Current use of any modern method of } \\
\text { contraception among currently married women } \\
15-49 \text { years \% }\end{array}$ & 26 & 51 & 25 & 0.355 & 0.196 & 0.641 & 53 & 67 \\
\hline & 12. ANC visit \% & 26 & 75 & 49 & 0.276 & 0.152 & 0.501 & 68 & $\mathrm{NI}$ \\
\hline & $13 . T T$ shots during pregnancy( 2 or more) $\%$ & 33 & 63 & 30 & 0.289 & 0.161 & 0.517 & 81 & $\mathrm{Nl}$ \\
\hline & 14.Delivery attended by skilled personnel \% & 10 & 19 & 9 & 0.473 & 0.208 & 0.078 & 43 & 60 \\
\hline \multirow{3}{*}{$\begin{array}{c}\text { GOAL } 6 \\
\text { Combat HIV/AIDS, } \\
\text { Malaria and other } \\
\text { diseases }\end{array}$} & $\begin{array}{l}\text { 15.Tuberculosis prevalence rate/100,000 } \\
\text { population }\end{array}$ & $310 \square$ & 280 & 30 & 1.107 & 0.942 & 1.302 & $\mathrm{Na}$ & $\begin{array}{l}\text { Halt and } \\
\text { reverse }\end{array}$ \\
\hline & 16. Malaria prevalence rate/100,000 population & $52 \square \square$ & 25 & 25 & 2.080 & 1.291 & 3.352 & $\mathrm{Na}$ & $\begin{array}{l}\text { Halt and } \\
\text { reverse }\end{array}$ \\
\hline & 17.Prevalence of HIV in age group 15-49 & $\mathrm{Na}$ & 0.5 & - & - & - & - & $\mathrm{Na}$ & $\begin{array}{l}\text { Halt and } \\
\text { reverse }\end{array}$ \\
\hline \multirow{2}{*}{$\begin{array}{c}\text { GOAL } 7 \\
\begin{array}{c}\text { Ensure environmental } \\
\text { sustainability }\end{array}\end{array}$} & 18.Access to drinking water(improved source) & 33 & 82 & 49 & 0.108 & 0.055 & 0.208 & $\mathrm{Na}$ & $68^{*}$ \\
\hline & 19. Access to sanitation \% & 20 & 42 & 22 & 0.412 & 0.223 & 0.760 & $\mathrm{Na}$ & 53 \\
\hline
\end{tabular}

Note: $\mathrm{Na}=$ Not available, $\mathrm{NI}=$ Not included, $\mathrm{OR}=$ Odds Ratio, $\mathrm{Cl}=$ Confidence Interval

$\square=$ The figures are for 2000 as no data was available for 1996

$\square \square=$ Universal access target is $100 \%$

* Indicators 1-3 and 18 and 19 are based on household questionnaire data, ${ }^{* *}$ Indicators 4-14 and 17 are based on women questionnaire data,

** Indicators 15 and 16 are based on MOHP data presented in a national MDG workshop in Kathmandu on February $10,2010$.

health service providers, 145 key informants, 104 exit clients at the service outlets and 400 focused group discussion participants from across 10 districts representing all five regions of Nepal [27]. The methods and tools of this study does not seem compatible to the NFHS 1996 and NDHS 2006. Moreover, the sample size of the NHRC study is relatively small. The results of the NHRC study however give a comparative picture on 6 out of 19 indicators included in Table 2. It offers data for supplementation to the NDHS 2006. The qualitative data from the NHRC study (2006) are used to supplement the analysis of the changes over time (where available and appropriate).

\section{Results}

Table 2 presents the key health indicators before the start of the violent conflict in 1996 and immediately after denouncement of violence by the Maoists in 2006. The data are presented into two sub-headings; health outcomes demonstrating improvement and health outcomes that remained stagnant or even worse during the decade-long conflict. 


\section{Health outcomes demonstrating improvement}

The data suggest that there has been progress in the reduction of stunting and underweight among children under three years (MDG 1), by 14\% (OR 1.756, CI 1.003-3.077) and 7\% ( OR 1.334, CI 0.759-2.381) respectively. In case of MDG 4, the infant and child mortality rates have dropped by $31 \%$ and $57 \%$ respectively and the coverage of childhood vaccines (intermediate indicators) increased over the years. Both DHS surveys show that coverage of DPT 3 and measles vaccines increased by $11 \%$ and $28 \%$ respectively, however the pace of progress appears to be slower. The coverage of DPT 3 and measles as shown by the NHRC study seems little higher (i.e. 93\% and 91\% respectively) than the NDHS 2006. It suggests likelihood of achieving the MDG targets by 2015 .

Similarly, the progress on two indicators of MDG 5 shows that achieving overall MDG 5 appears to be possible. The goal of reduction in maternal deaths is likely to be achieved as it reduced from 539 to 281 (OR 2.991, CI 2.484-3.602). The total fertility rate has dropped from 4.6 to 3.1 over the decade (OR 1.333, CI 0.298 5.959). Out of the four intermediate goals related to MDG 5, three goals (i.e. increase in modern contraceptive use, ANC visits and receiving Tetanus Toxoid vaccines (TT) by pregnant women are likely to be achieved. Between 1996 and 2006 contraceptive use increased by $25 \%$, ANC visits by $49 \%$ and the TT uptake by $30 \%$. The MDG 6 reversal and halting of tuberculosis and malaria could also be achieved as likelihood of the former seems to be 1.1 times higher (OR 1.107, CI 0.9421.302 ), while the latter is two times higher(OR 2.080,CI 1.291-3.352) in 2006 compared to the NFHS 1996.

The HIV prevalence in the 15-49 year age group was not available in NFHS 1996 which remained at 0.5\% in 2005 [32]. Table 2 suggests two targets under MDG 7 (access to drinking water and sanitation) are possible to achieve. The proportion of population with access to drinking water increased by $49 \%$ despite the conflict while increase in access to sanitation stood at $22 \%$.

Further indicators add the notion that Nepal is making progress in its health status such as the decrease in unmet need for family planning (31\% in $1996,25 \%$ in 2006) and the improvement in overall life expectancy from 56.5 years in 1996 to 63.3 years in 2006 [33].

\section{Health outcomes that remained stagnant/worse during the conflict}

Despite the progress in most health outcomes in Table 2 Nepal's goal of reducing the proportion of undernourished children was reversed by $4 \%$ over the period of violent conflict. The prevalence of under-nutrition however appears to be lower than the MDG 2015 target $(25 \%)$. Similarly the pace of reduction of the neonatal mortality rate (MDG 4) of $17 \%$ over the past decade suggests that reaching the neonatal mortality target for 2015 is going to be a serious challenge. Moreover, one of the indicators of the MDG 5-delivery attendance by skilled personnel increased by $9 \%$ against the reference year, which needs to be increased by $49 \%$ in order to achieve the MDG target of $60 \%$ in 2015 .

\section{Discussion}

From the point of view of the impact of the conflict, the data available from the two DHSs suggest more of a positive than of a negative impact on the health outcomes. The comparative data on 19 MDG-related indicators show that 16 out of 19 indicators had improved to such a level that MDG would be likely to be achieved by 2015 . While two indicators-reductions in neonatal mortality and improvement in skilled attendance at birth had increased at a slower pace, hence the related MDGs are unlikely to be achieved. One indicator, the percentage of undernourished children under three years old worsened in 2006 compared to the reference year 1996. Most of these findings on the trend of progress are compatible to the trends of health indicators shown in the MDG Progress Report published by Nepal's National Planning Commission in 2010 [32]. According to this report "Nepal is likely to meet the targets on reducing under five mortality by two-thirds, reduce the maternal mortality ratio by three quarters, halt and reverse the spread of HIV/AIDS, halt and reverse the incidence of malaria and other major diseases and halve proportion of population without sustainable access to improved water source. It is potentially likely to meet the targets on achieving universal access to treatment for HIV/AIDS for all those who need it. However, the report reiterates that Nepal is unlikely to meet the targets of achieving universal access to reproductive health and halving proportion of population without sustainable access to improved sanitation" [32].

Contrary to evidence from other conflicts [8,34-37] as well as from Nepal [38-40] of a negative impact of conflict on the health of populations, we found that in Nepal progress has been made in most health indicators. There does not appear much literature on what made it possible to achieve such progress despite a decade-long armed conflict. The discussion below explores the key drivers contributing to the better than expected changes in people's health status in a period of civil unrest and armed violence.

The first possible explanation is that Nepal's warring sides, in particular the former rebels, did not purposively disrupt the delivery of health services [41]. The health sector appeared to have been less susceptible to the violence. Besides few sporadic incidents, the overall 
political outlook of the rebels towards the health programmes and health workers was positive. Special national campaigns such as the National Immunisation Day for polio and measles immunisation, bi-annual vitamin supplementation and family planning camps were not much affected [16]. The key informant district health officers from Far-western districts expressed that the Maoist insurgents did not interrupt health activities in their districts.

Though the conflict had limited people's mobility for seeking our services particularly during transportation strikes (bandhs), they (Maoists) did not stop us from providing our services to the people (District Health Officer ID 5, Mid-western Region).

A second explanation is that the former rebels put pressure on the health care providers in their 'base areas' or the contested areas to attend regularly at clinics in order to ensure consistent drug supplies and treatment [42]. As a result, the government was under pressure to supply appropriate health staff and supplies. In spite of the security threat, $78 \%$ of staff positions in hospital, $75 \%$ in primary health care centres (PHCCs), $96 \%$ in health posts and $90 \%$ in sub-health posts were filled during the conflict [27].

Thirdly, conflict created an environment for improved coordination amongst the key actors: the MOHP, donors, civil society and the community representatives. One Local Development Officer's remark reflected this:

We have improved coordination between the district government and health representatives. We conduct regular meeting and discuss issues of local development, including those related to the health sector. (Key Informant ID 11)

The example of improved coordination despite the conflict in Nepal was also found during conflicts in East Timor [43] and Mozambique [37] where improved coordination amongst the key stakeholders helped increase utilisation of health services by the local population. In Nepal, it encouraged inclusive, people-based and transparent humanitarian programmes at the local level. Exemption of user fees to poor and disadvantaged populations and provision of citizen charters (agarics adapter) at service outlets could be taken as examples [27]. It also recognised the role of civil society and the local community groups in these health development activities.

Though the service guidelines have special provisions for poor and disadvantaged patients, there were problems however in defining them when it came to implementation $[27,44]$. One participant in a focused group discussion (FGD) said:

The service guideline directs us to providing free health services to the DAG (disadvantaged groups) and poor people but there are no clear definitions who they are. The decision depends on the discretion of the doctor attending the patient. (FGD 2, District ID 7)

Fourthly, building on the lessons from the protracted conflict, Nepal's public health system adopted a number of health improvement approaches and programmes. Some of the key policies focused on disadvantaged groups including dalits, women, disabled and elderly people, whilst helping to increase coverage of the health programmes in more remote and underserved areas. The policies also included the establishment of emergency funds and community drugs schemes and handing over the government ownership of the health facilities to the local communities [27].

Fifthly, Nepal strived to maintain a visible, sustained and adequate provision of health services at all levels from the centre to the community. There has been a substantial increase in the number of health care institutions, from 1,098 in 1991 to 4,552 in 2007/2008 [45]. The Government health facilities, such as health posts, sub-health posts, primary health care centres and outreach clinics provided basic community-based services, mostly free of charge. Nepal implemented many popular programmes such as the community-based integrated management of childhood diseases (CB-IMCI); community-based newborn care package(CB-NCB), community drug programme (CDP); direct observation treatment system (DOTS) for treatment of tuberculosis; HIV and AIDS prevention and control programmes; rural water supply and sanitation programme (RWSSP) and a food security programme. These initiatives helped increase access to and utilisation of the available health services $[27,32]$.

Sixthly, there was a functional community support system including the Health Facility Management Committees, mothers groups, Female Community Health Volunteers (FCHVs) and Traditional Birth Attendants (TBAs) for the mobilisation of local communities. One study showed that one-thirds of women were member of local women's groups, and that $43 \%$ members of the health facility management committees were from lower socio-economic groups such as Janajatis and dalits [27]. However, motivation and performance of these groups were often questionable in terms of their voluntariness as opposed to their desire for economic incentives, 
including the coping strategy in the context of the political conflict [46].

Seventhly, the UN (United Nations) and various international non-governmental organisations (INGOs) contributed for increasing the coverage and effectiveness of the health services in Nepal. They implemented conflictsensitive development programmes whilst keeping a low profile [47]. Nonetheless, in the absence of clear government policy and elected representatives, coordination between the government, development partners and the community people appeared to be poor [27].

Eighthly, development of infrastructures such as road, health facilities, schools, electricity, and communication might have contributed to the positive changes. One study found that despite the frequent transportation blocks due to strikes, more women living near main roads sought care from maternal health services [44]. Additional evidence is that access to health services increased over the years, for example travel time fell 50 times between 1995/96 and 2003/4 [21]. The NHRC study shows $83 \%$ women and $71 \%$ of service users reported having access to a health facility within 30 minutes' walk, with a further $16 \%$ of women and $14 \%$ of service users had reached within one hour on foot. Similarly, of the total service-users interviewed $51 \%$ in the terai, $45 \%$ in the hill area and $4 \%$ in the mountain districts had access to a road. However, focus groups with women from a remote district highlighted a lack of access to health services still existed.

People from here should either travel on horseback for four days, or fly to Pokhara (regional headquarter) via aeroplane to get treatment in a hospital. (FGD 1, District ID 13)

Increase in access to education and communication could have supported positive changes in health outcomes. During the decade of 1996-2006, adult literacy increased from 34\% in 1996 to $79 \%$ in 2006 [29,30]. The primary school enrollment rate increased from $57 \%$ to $73 \%$. In 1996, only $7 \%$ of all households had a radio and television, which increased to $28 \%$ in 2006 [33].

Ninthly, Nepal achieved a steady economic growth and substantial reduction in poverty. Between 1995/96 and $2005 / 6$, the percentage of the population living below the poverty line (US $\$ 1 /$ day) decreased from $42 \%$ to $31 \%$, and the absolute poverty dropped by one percentage points per year over the past couple of years. This somehow seems to contradict the economic explanation on the causation of conflict that underdevelopment and poverty fuels conflict [48-50]. However, a 2005 regional poverty profile shows that Nepal has varying regional deprivation levels. During 2003-2004, Kathmandu had the lowest level of poverty (3\%) while the other urban and rural areas had higher poverty levels i. e. $9.6 \%$ and $34.6 \%$ respectively [51]. The Nepal Living Standard Survey (NLSS II), 2003/2004 also reveals discrepancies in the distribution of poverty by development regions. It is lowest in the Central Development Region (27\%) and highest in the Mid-western Development Region (45\%), which is considered as the epicentre of the Maoist insurgency [52].

Economic inequality was reported between (a) the centre and the periphery; (b) the 'haves and have-nots; (c) different castes; and (e) people with different levels of education. For instance, in Kathmandu the average gross domestic product (GDP) was almost four times higher than that of some rural regions [52].

The increase in government's health sector budget, though only a small percentage change, might have helped towards achieving these health outcomes. The share of health sector budget increased from $5.99 \%$ in $1995 / 96$ to $6.41 \%$ in $2005 / 2006$ [32]. Moreover, the share of foreign aid of total government expenditure increased from $17.96 \%(2001 / 2002)$ to $19.88 \%$ in $2005 /$ 2006 and its contribution in Nepal's development expenditure increased from $58.07 \%$ to $74.45 \%$ [32]. Similarly, the share of foreign aid to GDP in the same period increased from $3.13 \%$ to $3.37 \%$ [32].These inputs would have contributed to the positive changes in the health indicators.

\section{Conclusion}

In spite of the violent conflict, Nepal made progress in 16 out of 19 health indicators over the period 19962006. The indicators of universal access to reproductive health, halving proportion of population without sustainable access to improved sanitation and proportion of underweight children has remained stagnant. We have outlined nine possible factors that help explain this phenomenon of seemingly improved health outcomes in a time of war. It is, of course, very likely that a combination of these nine factors interacted to create the positive environment in Nepal, despite, or perhaps because of its internal conflict.

The lessons from Nepal are that in order to ensure functional delivery of health services and improvement in health outcomes during conflict, the warring sides should adopt a strategy of coexistence and the international community should continue and increase their support to strengthen the health sector with a principle of 'do-no-harm' and impartiality and the government should implement conflict-sensitive measures and improve coordination amongst the key actors. Moreover, the overall national economic and social context should be conducive to bridging divides, and finally the government should work to fulfill its commitment towards the national policies and programmes and international 
instruments. It is equally important to reform the health services by building on Nepal's experience and consider the positive transformations that can occur as a result of conflict.

As this was the first comparative study that examined the health outcomes before and after the conflict and presented available evidences to explore the reasons for the positive changes, this paper provides general trend of health indicators overtime. Future studies should try to differentiate between conflict affected and peaceful areas and look at the conflict attributes that generate positive and negative consequences for the health services. Perhaps a little more focus is needed on the positive aspects as most of the studies conducted elsewhere portray negative consequences of conflict and ignore the transformation that occurs as a result of conflict.

\section{Acknowledgements \\ We would like to acknowledge organisations and individuals who conducted and disseminated findings of the NFHS 1996, NDHS 2006 and NHRC 2006. We would like to thank the MEASURE-DHS Calverton MD, for granting permission to use the NFHS 1996 and NDHS 2006 data. We are grateful to Jilly Ireland for proof reading the final submission.}

\section{Author details}

'Section of Population Health, School of Medicine and Dentistry, AB 25, 2ZD, University of Aberdeen, Scotland, UK. ${ }^{2}$ Associate Professor, Tribhuvan University, Kathmandu, Nepal. ${ }^{3}$ School of Health \& Social Care, Bournemouth University, Dorset BH1 3LT, Bournemouth, UK \& Visiting Professor, Manmohan Memorial Institute of Health Sciences, Nepal.

\section{Authors' contributions}

$\mathrm{BD}$ analysed the data and prepared draft of the paper. EVT finalised the manuscript of the paper.

Both the authors have read and approved the final manuscript.

\section{Competing interests}

The authors declare that they have no competing interests.

Received: 30 July 2010 Accepted: 1 December 2010 Published: 1 December 2010

\section{References}

1. Sidel VW, Levy BS: The health and social consequences of diversion of economic resources to war and preparation for war. In War or health? A Reader. Edited by: Taipale I. London 2004:1-4.

2. Tam CC, Lopman BA, Bornemisza O, Sondorp E: Epidemiology in conflict-A call to arms. Emerging Themes in Epidemiology 2004, 1:5.

3. Bornemisza O, Checchi F: Health interventions in crisis-affected communities of Nepal. Emergency and Humanitarian Action Programme, WHO Kathmandu 2006.

4. Murray CJ, Lopez AD: Mortality by cause for eight regions of the world Global Burden of Disease Study. The Lancet 1970, 349:1269-1276.

5. Fürst $T$, Giovanna R, Cinthia AA, Andres BT, Eliézer KN Utzinger GJ: Dynamics of socioeconomic risk factors for neglected tropical diseases and malaria in an armed conflict. PLoS Negl Trop Dis 3:e513[http://www. plosntds.org/article/info\%3Adoi\%2F10.1371\%2Fjournal.pntd.0000513].

6. Bhumann C, Santa-Barbara J, Neil A, Klus M: The roles of the health sector and health workers before, during and after violent conflict. Med Confl Surv 2010, 26:4-23.

7. Toole MJ, Waldman RJ: The public health aspects of complex emergencies and refugee situations. Annu Rev Public Health 1997, 18:283-312.

8. Vass A: Peace through health. BMJ 2001, 323:1020.
9. McDonnell SM, Bolton P, Sunderland N, Bellows B, White M, Noji E: The role of the applied epidemiologist in armed conflict. Emerg Themes Epidemiol 2004, 1:4.

10. Singh S, Sharma SP, Mills E, Poudel KC, \& Jimba M: Conflict induced internal displacement in Nepal. Med Confl Surv 2007, 23:103-110.

11. Stevenson PC: The torturous road to democracy-domestic crisis in Nepal. Lancet 2001, 358:752-756.

12. Singh $\mathrm{S}$, Bohler $\mathrm{E}$, Dahal $\mathrm{K}$, Mills $\mathrm{E}$ : The state of child health and human rights in Nepal. PLoS Medicine 2006, 3(7):e203.

13. Bohora A, Mitchell N, Nepal M: Opportunity, democracy and the exchange of political violence: A Sub-national analysis of conflict in Nepal. J Confl Resolution 2006, , 50: 108-128.

14. Massage I: No Habeas Corpus. In Himal Southasian. Volume 21. The South Asia Trust, Nepal; 2008:22-23.

15. Martinez E: Conflict related displacement in Nepal. Kathmandu: DFID 2002.

16. Mukhida K: Political crisis and access to health care: A Nepalese neurosurgical experience. Bulletin of the American College of Surgeries 2006, 91:19.

17. Maskey M: Practicing politics as medicine writ large in Nepal. Development 2004, 47:122-130.

18. Collins S: Assessing the health implications of Nepal's ceasefire. Lancet 2006, 368:907[http://www.thelancet.com].

19. The World Bank: An Assessment of impact of conflict on health services delivery system for the rural population of Nepal. Kathmandu. The World Bank, Kathmandu 2005.

20. The World Bank: Nepal poverty assessment. Washington DC 1994.

21. World Bank/DFID/ADB: Nepal resilience amidst conflict: an assessment of poverty in Nepal 1995-96 and 2003-04. Report No.34834 NP, Poverty Reduction and Economic management Sector Unit, South Asia Region 2006.

22. Singh S: Nepal's war and conflict-sensitive development. PLoS Medicine, Public Library of Science 2005, 2(1):e29.

23. Singh S: Impact of long-term political conflict on population health in Nepal. CMAJ 2004, 171:1499-501.

24. Kieveilitz U, Polzer T: Nepal country study on conflict transformation and peace building. Eschbom, Germany, GTZ 2002.

25. Pettigrew J, Delfabbro O, Sharma M: Conflict and health in Nepal: Action for peace building. Kathmandu, DFID, GTZ \& SDC 2003.

26. Sachs JD, McArthur JW: The Millennium Project: a plan for meeting the Millennium Development Goals. Lancet 2005, 365:347-53.

27. Devkota B: Effectiveness of essential healthcare services delivery in Nepal. J Nepal Health Res Council 2008, 6:74-83.

28. Polit DF, Hungler BP: Nursing Research-Principles \& Methods. JB Lippincot Co., Philadelphia; 41991.

29. Ministry of Health and Population (MOHP):New ERA, and Macro International Inc. 2007: Nepal Family Health Survey; 1996.

30. Ministry of Health and Population (MOHP)New ERA and Macro Internationallnc. 2007: Nepal Demographic and Health Survey 2006

31. Simkhada P, van Teijlingen E, Kadel S, Stephens J, Sharma S, Sharma M: Reliability of national data sets: Evidence from a detailed small area study in rural Kathmandu Valley, Nepal. Asian Journal of Epidemiology 2009, 2:44-48.

32. Government of Nepal/National Planning Commission, UN Country Team of Nepal: Nepal Millennium Development Goals Progress Report. Kathmandu 2010.

33. Pradhan A, Pant PD, Govindasami P: Trends in demographic and health indicators in Nepal. New Era/Macro International Inc., Calverton, Maryland USA; 2007.

34. McDonnell SM, Bolton P, Sunderland N, Bellows B, White M, Noji E: The role of the applied epidemiologist in armed conflict. Emerg Themes Epidemiol 1(4).

35. Murray CJ, Bishai D: Armed conflict as a public health problem: Current realities and future directions. USIP 2010 [http://www.usip.org/resources/ armed-conflict-public-health-problem-current-realities-and-future-directions], Accessed on May 21, 2010.

36. Murray CJL, King G, Lopez AD, Tomijama N, Krug EG: Armed conflict as a public health problem. BMJ 2002, 324[http://www.bmj.com].

37. Pavignani $\mathrm{E}$, Colombo A: Providing health services in countries disrupted by civil wars. A comparative analysis of Mozambique and Angola 19752000. World Health Organisation-EHA 2001 [http://www.who.int/disasters/ repo/14052.pdf], Accessed on June 29, 2009. 
38. Singh S, Dahal K, Mills E: Nepal's war on human rights: a summit higher than Everest. International Journal for Equity in Health 2005, 4:9.

39. Tol WA, Kohrt BA, Jordans MJD, Thapa SB, Pettigrew J, Upadhaya N, de Jong JTVM: Political violence and mental health: a multi-disciplinary review of the literature on Nepal. Soc Sc Med 2010, 70:35-44.

40. Stevenson PC: High-risk medical care in war-torn Nepal. Lancet 2002, 359:1495

41. Collins S: Assessing the Health Implications of Nepal's Ceasefire. Lancet 2006, 368:907-908

42. Devkota MD: An assessment on impact of conflict on delivery of health services. Kathmandu, The World Bank 2005.

43. Martins N, Kelly PM, Grace JA, Zwi AB: Reconstructing tuberculosis services. after major conflict: experiences and lessons learned in East Timor. PLoS Medicine 2006, 3:e383.

44. Thomas D, Messerschmidt D, Messerschmidt L, Devkota B: Evaluation of increasing access component. NSMP/Options, UK 2005.

45. WHO: Neglected health system research: health policy and systems research in conflict-affected fragile states. Research Issue 2008 [http:// www.who.int/alliance-hpsr/AllianceHPSR_Researchlssue_FragileStates.pdf].

46. Glenton C, IB Pradhan S, Lewin S Hodgins S, Shrestha V: The female community health volunteer programme in Nepal: decision makers' perceptions of volunteerism, payment and other incentives. Social Sc Med 2010, 70:1920-1927.

47. United Nations. Basic Operating Guidelines. 2010 [http://www.un.org.np/ resources/index.php].

48. Collier $\mathrm{P}, \mathrm{Hoeffler} \mathrm{A}$ : On economic causes of civil war. Oxford Economic Papers 1998, 50:563-573.

49. Devarajan S: South Asian Surprises, Keynote speech at the World Bank/ IMF/DFID conference on Macroeconomic policy challenges in low income countries Washington DC. 2005.

50. Macours K: Increasing inequality and civil conflict in Nepal. Johns Hopkins University 2009 [http://www.sais-jhu.edu/faculty/kmacours/2010/ macours_civilconflict_dec09.pdf], accessed on 25 May 2010.

51. SAARC Secretariat: SAARC Regional Poverty Profile. Kathmandu 2005.

52. Central Bureau for Statistics (CBS): Small area estimation of poverty, caloric intake and malnutrition in Nepal. Kathmandu 2006.

doi:10.1186/1752-1505-4-20

Cite this article as: Devkota and van Teijlingen: Understanding effects of armed conflict on health outcomes: the case of Nepal. Conflict and Health 2010 4:20

\section{Submit your next manuscript to BioMed Central and take full advantage of:}

- Convenient online submission

- Thorough peer review

- No space constraints or color figure charges

- Immediate publication on acceptance

- Inclusion in PubMed, CAS, Scopus and Google Scholar

- Research which is freely available for redistribution 